\title{
The Impact of Sociodemographic Factors vs. Gender Roles on Female Hospital Workers' Health: Do We Need to Shift Emphasis?
}

\author{
Doris Musshauser ${ }^{1}$, Angelika Bader ${ }^{1}$, Beatrice W ILdT $^{2}$ and Margarethe Hochleitner ${ }^{2}$
}

${ }^{1}$ Ludwig Boltzmann Institute for Gender Studies and ${ }^{2}$ Department of Internal Medicine, Innsbruck Medical University, Austria

\begin{abstract}
The Impact of Sociodemographic Factors vs. Gender Roles on Female Hospital Workers' Health: Do We Need to Shift Emphasis?: Doris Musshauser, et al. Ludwig Boltzmann Institute for Gender Studies, Austria-The aim of the present study was to evaluate the physical and mental health status of female workers from five different occupational groups and to identify possible sociodemographic and gender-coded family-related factors as well as work characteristics influencing women's health. The identified predictors of health status were subjected to a gender-sensitive analysis and their relations to one another are discussed. A total of 1083 female hospital workers including medical doctors, technical and administrative personnel, nurses and a group mainly consisting of scientific personnel and psychologists completed a questionnaire measuring work- and familyrelated variables, sociodemographic data and the Short-form 36 Health Questionnaire (SF-36). Data were analysed by multivariate regression analyses. Female medical doctors reported highest scores for all physical health dimensions except General Health. Our study population showed general low mental health status among administrative personnel and the heterogeneous group, others, scored highest on all mental health component scores. A series of eight regression analyses were performed. Three variables contributed highly significantly to all SF-36 subscale scores: age, satisfaction with work schedule, and the unpaid work variable. Age had the strongest influence on all physical dimensions except General Health ( $\beta=-$ $0.17)$ and had no detectable influence on mental health scores. The unpaid work variable $(\beta=-0.23 ; p<0.001)$ exerted a stronger influence on General Health than did age. Nevertheless, these variables were limited predictors of physical and mental health status. In all
\end{abstract}

Received Jan 20, 2006; Accepted Jul 5, 2006

Correspondence to: D. Musshauser, Ludwig Boltzmann Institute for Gender Studies, Innrain 66/II, A-6020 Innsbruck, Austria (e-mail: doris.musshauser@tilak.at) occupational groups the amount of time spent daily on child care and household tasks, as a traditional gendercoded factor, and satisfaction with work schedule were the only contributors to mental health among working women in this study. Traditional sociodemographic data had no effect on mental health status. In addition to age, these factors were shown to be the only predictors of physical health status of female workers. Gender coded-factors matter. These findings underline the importance of including gender-coded family- and workrelated variables in medical research over and above basic sociodemographic data in order to describe study populations more clearly. (J Occup Health 2006; 48: 383-391)

Key words: Female hospital workers, Short-form 36 Health Questionnaire (SF-36), Work schedule, Volume of domestic duties

Recent years have seen an increasing number of studies conducted and published on the differences between women and men with regard to health and medical disorders, symptoms, therapy and outcome ${ }^{1-2)}$. Such studies and their results fall under the heading gender studies, although only very few studies provide definition of the term gender. Sex and gender are frequently used in an interchangeable way. However, a precise definition of these terms is needed if all areas of science are to be gender-sensitive in future:

Gender refers to women's and men's roles and responsibilities that are socially and culturally determined, whereas sex denotes the genetic/physiological or biological characteristics of a person ${ }^{3)}$.

A large number of facts and factors and their interrelationships have been used to explain gender-based health differences between women and men. These include biological, social, cultural, economic factors, and even work conditions ${ }^{1-2,4-8)}$

Of these interrelationships, several factors can be ascribed to so-called gender roles, namely economic and 
social roles which a society considers appropriate for men and women, vary between cultures and can change over time $^{3)}$. Women usually have several roles ranging from domestic responsibilities to community activities to paid productive work. Many women pursue what society typically calls female occupations, such as those in healthcare. Only a few studies have examined and compared the health status and predictors of the health status of female hospital staff from all occupational groups $^{9-12)}$.

A literature review indicates that differences in employment status and family structure are associated with psychosocial and physical health inequalities in women, especially when the influence of marital, parental and employment circumstances and their development over time were taken into account when examining women's health ${ }^{4-6)}$. Women still assume most of the responsibility for domestic (unpaid) work including child care and household duties. The double burden caused by high levels of domestic responsibility is shown to have adverse effects on the status of women's health ${ }^{7-8)}$. These findings emphasize the need to strongly investigate gender-coded factors influencing the well-being of employed women ${ }^{13)}$.

Gender-coded factors refer to all types of social variables that differ between men and women due to their assigned gender role, like the volume of domestic duties.

Not only do family commitments affect health, but also work satisfaction ${ }^{14,15)}$ and organizational aspects of work. Among the organizational factors, not only working hours but also work schedule remains important. Night and weekend shifts and shift work itself are known to cause psychological $^{16)}$ and physical impairment ${ }^{17)}$. Still, night shifts pose an alternative for many working women, especially female hospital workers, mainly nurses, to combine family duties and work. Similarly, the consistent interest in and choice of part-time work among women reflect gender-coded expectations in the fields of work and family ${ }^{18,19)}$.

However, the ability to choose the preferred number of working hours gives better outcomes in work-, familyand health-related factors ${ }^{20)}$.

A study by Emslie et al. (1999) showed that, although the relationship between work characteristics and morbidity is similar for men and women employed in similar circumstances in one organization, gender differences remained associated with morbidity ${ }^{21}$.

The interrelations between gendered domestic roles, sociodemographic variables and paid work characteristics lead us to conclude that the health and medical disorders of women and men are influenced by different factors.

The first aim of the present study was to assess the physical and mental health status of a female working population of one organization and to show potential health differences between five different occupational groups. This study was conducted at a medical university hospital in Austria. A hospital was deemed a suitable place to study the health of working women, because the majority of persons employed are women and they largely work in female-gendered jobs, particularly nursing. The second aim of the study was to identify possible factors affecting the health of working women. Associations between selected sociodemographic data, gender-coded family-related factors as well as work characteristics and health are presented.

Differences in the identified health-influencing factors between all five occupational groups were also examined in order to determine any job-specific characteristics.

Finally, the factors influencing the health of working women were subjected to a gender-sensitive analysis and their relations to one another are discussed.

\section{Materials and Methods}

\section{Study population}

The Women's Health Office of Tyrol, Austria, conducted the present study during a three-month period in 2004 among the female personnel of Innsbruck Medical University Hospital. A total of 2,000 questionnaires were distributed to representatives of all wards and hospital facilities. All representatives were requested to distribute the questionnaires to the female personnel in their department who would be working at that particular department during the three months of the study. Of the distributed questionnaires, 1,083 were anonymously completed by female hospital staff, collected by the representatives and returned to the researchers. This represents a $54.2 \%$ response rate.

A total of 1,083 women answered the questionnaire. The study population ultimately consisted of female medical doctors $(n=98)$, technical personnel $(n=145)$, nurses ( $\mathrm{n}=667)$, administrative personnel $(\mathrm{n}=92)$ and other female hospital workers $(n=81)$, a group mainly comprising scientific personnel and psychologists.

\section{Research instruments}

Sociodemographic and gender-coded family-related variables: Age was measured in years and broken down into six groups: to $19 \mathrm{yr}$; 20-29 yr; 30-39 yr; 40-49 yr; $50-59 \mathrm{yr}$ and $60 \mathrm{yr}$ and above. Classification of parental status was based on the number of children and their age. Female hospital workers' family commitments were assessed by (a) the volume of domestic duties as defined by the number of hours per day spent on household tasks and child care (the unpaid work variable), (b) whether responsibility for child care was shared or carried alone, and (c) the perceived amount of weekly free time in hours.

Measurement of work-related variables: Employment status was defined as part- (1-29 h per week) or fulltime work ( $30 \mathrm{~h}$ or more per week). Additionally, 
participants were asked to indicate whether they would prefer a different work schedule with regard to their work satisfaction and family commitments. Information on an existing long-term contract and the intention to change profession or give up hospital work was also requested.

Potential negative effects of night and weekend shifts and of work itself on psychosocial and physical wellbeing were measured on a four-point scale (from 1="very strong influence", to 4="no influence").

Women's level of work satisfaction was measured on a four-point scale, scoring from 1, "very satisfied", to 4, "not satisfied at all". Additionally, two components of work satisfaction were selected ${ }^{22,23)}$ : (a) About their career opportunities, the respondents were asked: "Do you see career advancement possibilities?"; (b) A four-point scale was used to measure desired higher income.

Measurement of health status: The German (Austrian) Medical Outcomes Study 36-item Short Form Health Survey, SF-36, version 1.0, was used to examine the health status of the study sample ${ }^{24,25}$. The SF-36 is a valuable instrument, well proven to examine potential associations between (gender-coded) work characteristics and (gendercoded) family-related factors and health ${ }^{26,27)}$.

The following eight dimensions of the instrument were assessed: Physical Functioning (PF); Role Physical (RP); Bodily Pain (BP); self-assessed perception of General Health; Vitality (VT); Social Functioning (SF); Role Emotional (RE); and Mental Health (MH). Because of described methodological and factorial difficulties it was decided to not calculate the SF-36 summary scores, the Physical Component Summary (PCS) or the Mental Component Summary (MCS) ${ }^{28,29)}$.

In compliance with the SF-36 manual ${ }^{30)}$ all scales were transformed using SF Health Outcomes ${ }^{\mathrm{TM}}$ Scoring Software. The scores range from 0 to 100. A higher score indicates better health. Missing values were estimated and substituted according to the SF-36 manual.

Statistical analysis: Data analysis was performed using SPSS 12.0 software. To address generalization of independent variables, bivariate correlations for all occupational subgroups were performed with SF-36 variables.

Sociodemographic, work-related and gender-coded family-related variables with at least moderate and unidirectional correlations in all subgroups were selected. In addition, variables already known to influence health status were included in the multivariate analysis. In a second step to exclude confounding variables, a multivariate linear regression analysis was performed to identify independent factors. SF-36 subscale scores were used as dependent variables. Durbin-Watson statistics indicated no serial correlation of variables (maximum 2.05, minimum 1.99). Collinearity was tested by assessing the variance inflation factor that ranged from a maximum of 2.07 to a minimum of 1.02. All significance levels were Bonferroni-adjusted and set at $p=0.05$. To check linearity of the regression models, histogram analysis of standardized residuals was performed and it showed normal distributions (data not shown). Independent missing variables (maximum $4.7 \%$ for "satisfaction with work load", minimum $0.8 \%$ for "marital status") were included as dummy variables in the multivariate analysis and showed no significant influence on the dependent health scores.

\section{Results}

Sociodemographic characteristics of all five occupational groups are presented in Table 1 . The majority of our study population was concentrated in the younger age groups (20-39 yr). There was a marked decline in female doctors and administrative personnel above the age of $40 \mathrm{yr}$. A decline in the number of female technical staff and nurses was already found above the age of $30 \mathrm{yr}$.

A total of 474 (43\%) female hospital workers reported spending one to four hours per day on household tasks and child care (the unpaid work variable). Remarkably, $161(14 \%)$ women spent even more than four hours a day on domestic duties.

For the purpose of comparison of the health status of the various occupational groups in our sample, Table 2 presents the mean scores and standard deviations for the eight domains of the SF-36 not adjusted for age. The highest scores on all dimensions of mental health were found among female administrative personnel and the heterogeneous group, Other. Additionally, the lowest scores on Mental Health dimensions (apart from Role Emotional) and General Health were reported by female medical doctors. The differences between medical doctors and administrative personnel ranged from 3.8 points (Mental Health) to 7.6 points (Vitality). The lowest score on Role Emotional was found among female technical personnel. The differences between technical personnel and the other occupational groups ranged from 6.8 points (nurses) to 14.8 points (other). Medical doctors had the highest scores for all physical health dimensions except General Health. The differences between the other occupational groups ranged from 3.2 points for Role Physical to 4.2 points for Bodily Pain, where nurses reported the lowest scores. Although nurses were younger than medical doctors, technical and administrative personnel, they did not report better health than the other occupational target groups.

To identify predictors of women's health, correlations were established between sociodemographic, gendercoded family-, specific work-related variables and the eight SF-36 subscales (data not shown). The results of the bivariate correlation for all occupational subgroups 
Table 1. Selected sociodemographic characteristics. Values are absolute numbers (percentages)

\begin{tabular}{|c|c|c|c|c|c|c|c|}
\hline & \multicolumn{2}{|c|}{$\begin{array}{l}\text { Medical } \\
\text { Doctors }\end{array}$} & $\begin{array}{l}\text { Technical } \\
\text { Personnel }\end{array}$ & Nurses & $\begin{array}{c}\text { Administrative } \\
\text { Personnel }\end{array}$ & Other & Total \\
\hline Characteristics & \multicolumn{2}{|c|}{$\mathrm{n}(\%)$} & $\mathrm{n}(\%)$ & $\mathrm{n}(\%)$ & $\mathrm{n}(\%)$ & $\mathrm{n}(\%)$ & $\mathrm{n}(\%)$ \\
\hline \multicolumn{8}{|l|}{ Gender } \\
\hline Female & 98 & $(100)$ & $145(100)$ & $667(100)$ & $92(100)$ & $81(100)$ & 1083 (100) \\
\hline \multicolumn{8}{|l|}{ Age (yr) } \\
\hline$\leq 19$ & 0 & $(0.0)$ & $3(2.1)$ & $0 \quad(0.0)$ & $1 \quad(1.1)$ & $7 \quad(8.6)$ & 11 (1.0) \\
\hline $20-29$ & 19 & (19.4) & $49(33.8)$ & $290(43.5)$ & $20(21.7)$ & $26(32.1)$ & $404(37.3)$ \\
\hline $30-39$ & 47 & $(47.9)$ & $44(30.3)$ & $190(28.5)$ & $38(41.3)$ & $23(28.4)$ & 342 (31.6) \\
\hline $40-49$ & 29 & $(29.6)$ & $30(20.7)$ & $118(17.7)$ & $21(22.8)$ & $20(24.7)$ & $218(20.1)$ \\
\hline $50-59$ & 3 & (3.1) & $19(13.1)$ & $69(10.3)$ & $12(12.2)$ & $4 \quad(4.9)$ & $107 \quad(9.9)$ \\
\hline$\geq 60$ & 0 & $(0.0)$ & $0 \quad(0.0)$ & $0 \quad(0.0)$ & $0 \quad(0.0)$ & $1 \quad(1.2)$ & $1 \quad(0.1)$ \\
\hline \multicolumn{8}{|l|}{ Marital Status } \\
\hline Single & 61 & $(62.2)$ & $101(69.6)$ & $421(63.1)$ & 43 (46.7) & $54(66.7)$ & $680(62.8)$ \\
\hline Married & 28 & $(28.6)$ & 33 (22.7) & 184 (27.6) & $33(35.9)$ & $22(27.2)$ & $300(27.7)$ \\
\hline Divorced & 9 & $(9.2)$ & $11(7.6)$ & $47 \quad(7.0)$ & $14(15.2)$ & $5 \quad(6.2)$ & $86 \quad(7.9)$ \\
\hline Widowed & 0 & $(0.0)$ & $0 \quad(0.0)$ & $6 \quad(0.9)$ & $2 \quad(2.2)$ & $0 \quad(0.0)$ & $8 \quad(0.7)$ \\
\hline No Answer & 0 & $(0.0)$ & $0 \quad(0.0)$ & $9 \quad(1.3)$ & $0 \quad(0.0)$ & $\begin{array}{ll}0 & (0.0)\end{array}$ & $9 \quad(0.8)$ \\
\hline \multicolumn{8}{|c|}{ Number of children } \\
\hline 0 & 62 & $(63.3)$ & $103(71.0)$ & 447 (67.0) & $44(47.8)$ & $54(66.7)$ & $710(65.5)$ \\
\hline 1 & 15 & $(15.3)$ & $10(6.9)$ & 97 (14.5) & $21(22.8)$ & $11(13.6)$ & $154(14.2)$ \\
\hline 2 & 18.4 & $(18.4)$ & $26(17.9)$ & $98(14.7)$ & $25(27.2)$ & $12(14.8)$ & $179(16.5)$ \\
\hline $3-5$ & 3 & (3) & $6(4.2)$ & $25 \quad(3.7)$ & $2(2.2)$ & $4 \quad(4.9)$ & $40 \quad(3.7)$ \\
\hline
\end{tabular}

Table 2. SF-36 means and standard deviations broken down by occupation

\begin{tabular}{lcccccc}
\hline SF-36 domains & $\begin{array}{c}\text { Medical } \\
\text { Doctors }\end{array}$ & $\begin{array}{c}\text { Technical } \\
\text { Personnel }\end{array}$ & Nurses & $\begin{array}{c}\text { Administrative } \\
\text { Personnel }\end{array}$ & Other & Total \\
\hline Physical Functioning & $95.9(6.5)$ & $93.1(11.8)$ & $92.4(11.2)$ & $91.6(11.6)$ & $93.2(11.2)$ & $92.8(11.0)$ \\
Role Physical & $85.0(22.6)$ & $83.1(28.4)$ & $82.6(30.4)$ & $84.2(31.2)$ & $81.8(30.6)$ & $83.0(29.6)$ \\
Bodily Pain & $81.2(23.5)$ & $80.1(23.8)$ & $77.0(25.9)$ & $80.5(26.4)$ & $80.4(27.2)$ & $78.4(25.6)$ \\
General Health & $73.1(14.8)$ & $73.8(17.8)$ & $73.9(17.2)$ & $75.9(19.7)$ & $77.6(18.4)$ & $74.2(17.4)$ \\
Vitality & $52.1(18.5)$ & $54.8(17.4)$ & $57.5(18.5)$ & $59.7(23.4)$ & $60.5(16.9)$ & $57.1(18.8)$ \\
Social Functioning & $76.1(23.4)$ & $78.7(22.7)$ & $79.4(22.7)$ & $81.8(23.8)$ & $84.1(21.3)$ & $79.6(22.8)$ \\
Role Emotional & $60.1(43.8)$ & $52.5(44.4)$ & $58.7(45.0)$ & $62.9(44.3)$ & $67.0(41.3)$ & $59.0(44.5)$ \\
Mental Health & $70.3(22.6)$ & $73.8(25.4)$ & $76.5(23.3)$ & $74.1(28.6)$ & $75.9(19.0)$ & $75.3(23.8)$ \\
\hline
\end{tabular}

are available from the author on request. Four workrelated variables (night and weekend shifts; higher income desired; career chances; satisfaction with work schedule), three sociodemographic variables, age, marital status and number of children, and the unpaid work variable, domestic duties, were selected and included as independent variables in a multivariate analysis. A series of eight regression analyses were performed.

The standardized regression coefficients (beta) and conventional levels of significance are $\left({ }^{*} \mathrm{p}<0.05 ;{ }^{* *} \mathrm{p}<0.01\right.$; $\left.{ }^{* * *} \mathrm{p}<0.001\right)$ presented in Table 3 . The combination of the eight independent variables accounted for $1 \%$ to $12 \%$ of the variation in health variables. All models except Role Emotional were highly significant $(\mathrm{p}<0.001)$. Three variables contributed highly significantly to the SF-36 subscale scores, namely age, satisfaction with work schedule, and the domestic duties. The adjusted $\mathrm{R}^{2}$ indicate that $12 \%$ of the variance of Physical Functioning scores was explained by age $(\beta=-0.31)$ and domestic duties $(\beta=-0.14)$. However, satisfaction with work schedule and domestic duties explains only $5 \%$ of the variance for Vitality and 6\% for Social Functioning.

Age contributed to all four physical health dimensions (Physical Functioning, Role Physical, Bodily Pain and 
Table 3. Multivariate regression analysis of the relationships between work- and family-related variables, sociodemographic data and the eight SF-36 domains

\begin{tabular}{|c|c|c|c|c|c|c|c|c|}
\hline & $\begin{array}{l}\text { Physical } \\
\text { Functioning }\end{array}$ & $\begin{array}{c}\text { Role } \\
\text { Physical }\end{array}$ & $\begin{array}{l}\text { Bodily } \\
\text { Pain }\end{array}$ & $\begin{array}{c}\text { General } \\
\text { Health }\end{array}$ & Vitality & $\begin{array}{c}\text { Social } \\
\text { Functioning }\end{array}$ & $\begin{array}{l}\text { Role } \\
\text { Emotional }\end{array}$ & $\begin{array}{l}\text { Mental } \\
\text { Health }\end{array}$ \\
\hline \multicolumn{9}{|l|}{$\beta$} \\
\hline \multicolumn{9}{|l|}{ Sociodemographic Data } \\
\hline Age & $-0.31^{* * *}$ & $-0.15^{* *}$ & $-0.22^{* * *}$ & $-0.17^{* *}$ & -0.01 & -0.07 & -0.06 & -0.05 \\
\hline Marital status & 0.04 & 0.07 & 0.03 & 0.05 & 0.08 & 0.05 & 0.03 & 0.05 \\
\hline Number of children & 0.05 & 0.00 & 0.09 & 0.12 & 0.07 & 0.04 & 0.02 & 0.05 \\
\hline \multicolumn{9}{|l|}{ Work-related variables } \\
\hline Night and weekend shifts & -0.05 & -0.02 & -0.08 & -0.04 & -0.02 & -0.01 & 0.00 & 0.00 \\
\hline Higher income desired & 0.04 & 0.02 & 0.05 & 0.02 & 0.04 & 0.07 & 0.00 & -0.01 \\
\hline Career opportunities & -0.08 & -0.05 & -0.06 & -0.07 & -0.10 & -0.06 & -0.03 & -0.07 \\
\hline Satisfaction with work schedule & -0.04 & $-0.11^{*}$ & -0.09 & $-0.11^{*}$ & $-0.16^{* * *}$ & $-0.15^{* * *}$ & -0.07 & -0.10 \\
\hline \multicolumn{9}{|l|}{ Unpaid work variable } \\
\hline Domestic duties & $-0.14^{* *}$ & $-0.14^{*}$ & $-0.19^{* * *}$ & $-0.23^{* * *}$ & $-0.17^{* * *}$ & $-0.17^{* * *}$ & -0.08 & $-0.15^{*}$ \\
\hline Adjusted $\mathrm{R}^{2}$ & 0.12 & 0.06 & 0.09 & 0.08 & 0.05 & 0.06 & 0.01 & 0.03 \\
\hline $\mathrm{F}$ & $17.7^{* * * *}$ & $8.2^{* * *}$ & $12.4^{* * *}$ & $10.7^{* * *}$ & $7.8^{* * *}$ & $8.2^{* * *}$ & 1.9 & $4.7^{* * *}$ \\
\hline
\end{tabular}

${ }^{*} \mathrm{p}<0.05,{ }^{* *} \mathrm{p}<0.01,{ }^{* * *} \mathrm{p}<0.001$

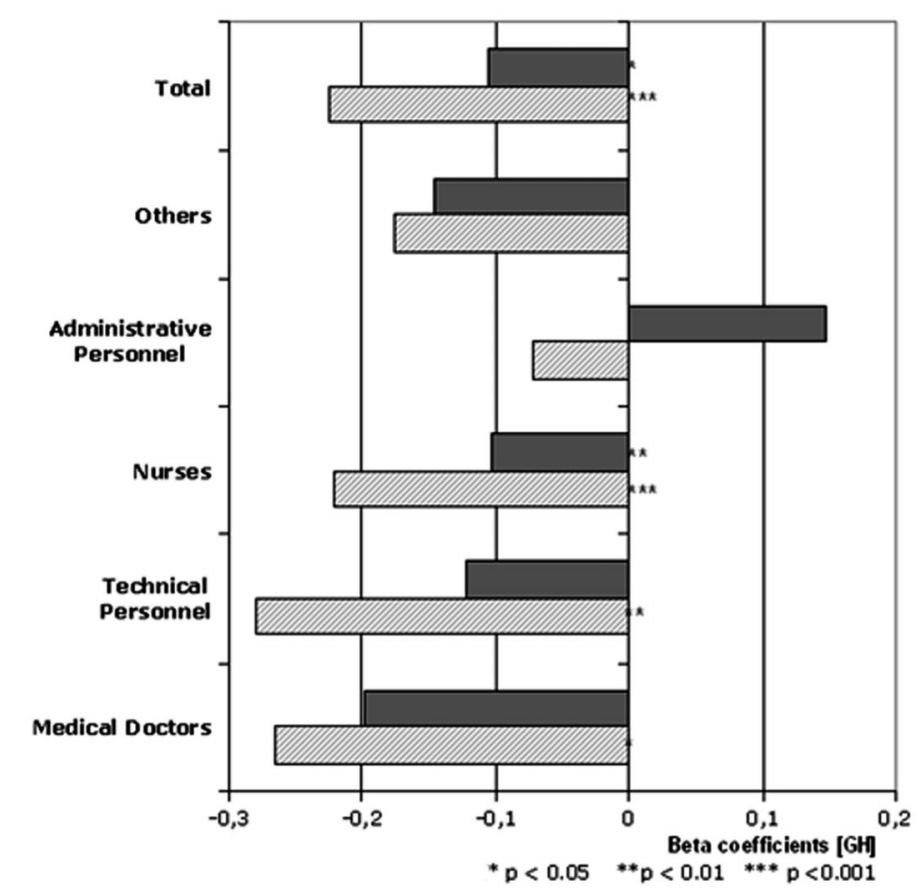

Fig. 1. Satisfaction with work schedule (gray bars) and "unpaid work" variable (striped bars) affecting general health $(\mathrm{GH})$ by multiple regression analysis for various occupational groups.

General Health). Higher age was associated with lower physical health-related SF-36 scores and had no detectable influence on mental health scores. Age showed a stronger influence on all physical dimensions except General Health than did the two other predictive variables.
Domestic duties $(\beta=-0.23 ; \mathrm{p}<0.001)$ exerted a stronger influence on General Health than did age. Nevertheless, these variables explain only $8 \%$ of the score variance. Low satisfaction with work schedule predicted lower scores for Role Physical, General Health, Vitality and 


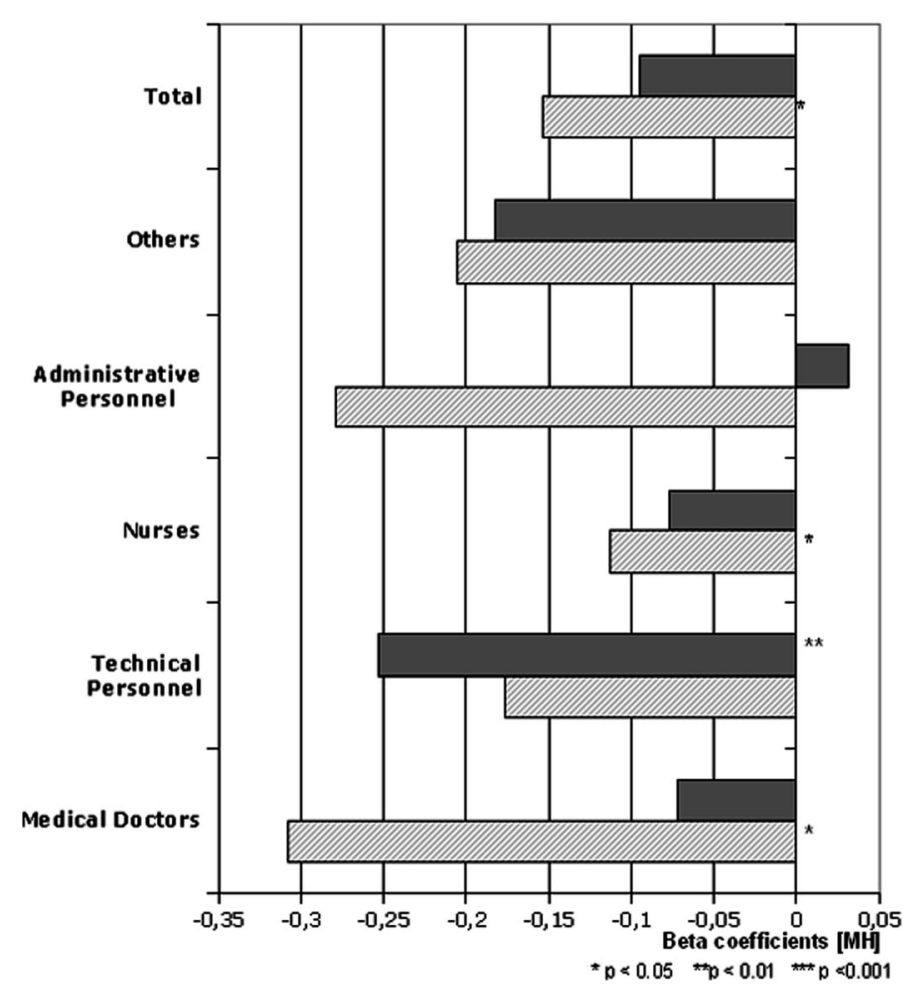

Fig. 2. Satisfaction with work schedule (gray bars) and "unpaid work" variable (striped bars) affecting mental health (MH) by multiple regression analysis for various occupational groups.

Social Functioning. In addition to these two independent variables, the only variable contributing significantly $(p<0.05$ to $p<0.001)$ to seven of the eight dimensions of SF-36 was domestic duties. The greater the number of hours per day spent on household tasks and child care, the worse the health status was. Health score decline per hour of domestic duties per day performed by a female hospital worker ranged from 1.4 score points for Physical Health to 4.6 score points decline for Bodily Pain, as measured by the non-adjusted B-coefficient.

Additionally, multivariate regression analyses using the same selected dependent and independent variables as for the total study sample were performed separately for the various occupational groups. Two results were selected and are presented in Figs 1 and 2. They show the beta coefficients for the General Health (Fig. 1) and Mental Health (Fig. 2) models and conventional levels of significance for each occupational group. The results of the regression analyses for the other SF-36 health dimensions are not shown but are available from the author. The direction of the bars illustrates the negative beta coefficients, showing that low satisfaction with work schedule and high volume of domestic duties are associated with poorer General Health and Mental Health in all occupational groups except administrative personnel, although the positive beta found in all eight SF-36 dimensions has no statistical significance for the variable, satisfaction with work schedule.

\section{Discussion}

The aim of our study was to present the health status of the vast majority of hospital workers, namely women, and to investigate the influence of gender-coded family related, work-related and sociodemographic variables on their physical and mental health.

Unfortunately, the health questionnaire, SF-36, has not been applied to a healthy population in Austria to date. Therefore, no normative, comparable data are available. In comparison to a Greek study ${ }^{12)}$, female Austrian hospital workers reported higher average health status scores for all dimensions of the SF-36 except Vitality and Role Emotional. These results correspond with the results of a study conducted in New Zealand among male and female nurses ${ }^{27)}$.

The lowest levels of all SF-36 dimensions among the female personnel were reported for Vitality and Role Emotional. The female technical group reported by far the lowest levels for Role Emotional with the greatest differences to the other occupational groups. Most published studies on occupations in the health sector have 
been conducted among nurses or medical doctors. Since hardly any studies have been conducted on the physical and mental health status of technical personnel, laboratory technicians, radiological technicians etc. in hospitals, further studies are certainly needed to precisely investigate the low levels in the mental health dimensions, Role Emotional and Vitality, in this occupational group ${ }^{31,32)}$.

Low levels of physical health ${ }^{33)}$ among nurses and administrative personnel account for high levels of physical burden, as does the unhealthy, sedentary type of job among female administrative personnel ${ }^{34)}$. Better mental health among the administrative personnel can be explained by less psychosocial strain from workrelated circumstances like the high level of responsibility involved in patient contact and care. We are aware that no information on comorbid conditions or health behavior was obtained or included in our model. However, we believe the so-called "healthy worker effect" ${ }^{35)}$ also applies to female hospital personnel. Moreover, a study by Wensing et al. (2001) showed that the influence of comorbidity on functional health status was not strong and only a small portion of the variation of the SF-36 dimensions was associated with having a health problem $^{36)}$.

The second aim of the study was to investigate working women's health-influencing factors. Of the studied workrelated, gender-coded family-related factors and sociodemographic variables, only three were highly significantly associated with the SF-36 subscale scores: age, satisfaction with work schedule and the unpaid work variable, domestic duties.

It should be noted that the independent variables in this study predicted a relatively small amount of the total variance in female hospital workers' physical and mental health. This finding is in agreement with previous studies showing that the influence not only of sociodemographic but also of work-related factors on self-assessed health is moderate. Our study also provides further evidence supporting the results of previous studies ${ }^{37-39)}$.

Nevertheless, when we look at the sociodemographic variables, the only one that was highly significantly associated with all physical health dimensions was age. Higher age had a negative effect on Physical Functioning, Role Physical, Bodily Pain and General Health. This effect was relatively strong for Physical Functioning and Bodily Pain. This study showed no association between age and mental health status. These findings are in agreement with the literature, which shows increasing age to have a stronger influence on physical functioning than on mental health ${ }^{36,40,41)}$. Neither the number of children nor respondents' marital status had any effect on the self-assessed health status. These results stand in contrast to those of a study by Emslie et al. (1999) that showed that being formally married was associated with poorer General Health scores ${ }^{21)}$.
The only work-related factor significantly associated with four dimensions of the SF-36 was satisfaction with work schedule. In addition to the unpaid work variable, domestic duties, working the preferred number of hours is above all a strong predictor of the two mental health dimensions Social Functioning and Vitality. It has been shown that women physicians ${ }^{20)}$ who were satisfied with their work schedule reported less burnout and greater life satisfaction. Due to their gender role, it is unfortunately still largely working mothers and not fathers, who are forced to decide between full- and part-time work in order to juggle family and job. From this standpoint, the variable, satisfaction with work schedule, can be seen as a gender-coded factor. The gender bias in this issue is also reflected in the existing literature, which almost exclusively deals with women ${ }^{18-20)}$.

To determine the effect of gender-coded family-related factors we used volume of domestic duties, and distribution of the responsibility for child care. The gender-coded and in relation to the other investigated factors stronger health-influencing factor identified was volume of domestic duties. Women are still the main providers of child care and household work ${ }^{7,8)}$. A greater number of hours spent daily on child care and household tasks by the female hospital personnel was associated with lower scores on all SF-36 dimensions except Role Emotional. These results agree with those of a study by Escriba-Agüir JM et al. (2004), who investigated only the effects of domestic chores on mental health dimensions of the SF-36 among hospital workers ${ }^{42)}$. The present study also showed an effect on all physical health dimensions. Volume of domestic duties was an even stronger predictor of General Health than was age. Our study supports the results of other studies, in which great domestic responsibility is associated with a higher degree of common symptoms ${ }^{7,42,43)}$.

These findings were constant for all five occupational groups studied: a high volume of domestic duties and greater dissatisfaction with work schedule were associated with poorer health, with the exception of the occupational group of administrative personnel, where satisfaction with work schedule did not necessarily have a negative influence on health, which could have implications for further studies. One possible explanation for this result is that administrative personnel probably, more commonly, have the desired working hours than do the other occupational groups. In all occupational groups, number of hours spent on domestic duties, a traditional gender-coded factor, and satisfaction with work schedule were the only contributors to mental health among working women in this study. Traditional sociodemographic data had no effect on mental health status. In addition to age, these factors were shown to be the only predictors of physical health status of the female workers. Gender coded-factors matter ${ }^{13)}$. 
This study had a number of limitations. First, data are from one geographic region. The results could vary in comparison to other regions and may not be generalizable. Second, comparison of the SF-36 scores is not yet possible, because national norms have not been published. The investigated study sample cannot be seen as representative of the Austrian population. The study was conducted on a specific group of women, within which five different occupational groups were studied. However, no men were included in the presented study, because the aim of the study was not to identify gender differences. In a further study, however, it would be important to examine the investigated factors, gendercoded or not, in connection with men's health. The crosssectional design of the study does not allow us to conclude causality. The female working target group with poorer mental or physical health may report more negative feelings about their satisfaction with work schedule and may attach more significance to the volume of domestic duties. The study sample may suffer from selection bias caused by the representatives of the wards or hospital facilities, who may not have reached or recruited all working women, which might explain the response rate.

Low satisfaction with work schedule and amount of time spent daily on child care and household tasks, as a traditional gender-coded factor, were identified as having some predictive value for female hospital workers' physical and above all mental health, irrespective of occupation. The effect of these variables, above all on mental health status, is stronger than that of traditional sociodemographic variables like age.

Although these variables are of limited value in guiding clinical practice, these findings underline the importance of including gender-coded variables in medical research over and above basic sociodemographic data in order to describe a study population more clearly. However, further studies aimed at identifying gender-coded healthinfluencing factors are worth the effort, not only for female hospital workers but for all women and men in the workforce.

Acknowledgments: Basic funding was provided by the Ludwig Boltzmann Institute for Gender Studies (Innrain 66, A-6020 Innsbruck, phone +43.512.504.25710, fax $+43.512 .504 .25719)$.

\section{References}

1) Legato MJ, ed. Principles of Gender-Specific Medicine. San Diego: Elsevier Academic Press, 2004.

2) Rieder A, Lohff B, eds. Gender medizin. Wien: Springer Verlag, 2004 (in German).

3) World Health Organization. Gender and Health: Technical Paper. Geneva: WHO, 1998.

4) Arber S: Comparing inequalities in women's and men's health: Britain in the 1990s. Soc Sci Med 44, 773-787 (1997)
5) Khlat M, Sermet C and Le Pape A: Women's health in relation with their family and work roles: France in the early 1990s. Soc Sci Med 50, 1807-1825 (2000)

6) Lahelma E, Arber S, Kivela K and Roos E: Multiple roles and health among British and Finnish women: the influence of socioeconomic circumstances. Soc Sci Med 54, 727-740 (2002)

7) Krantz G and Ostergren PO: Double exposure. The combined impact of domestic responsibilities and job strain on common symptoms in employed Swedish women. Eur J Public Health 11, 413-419 (2001)

8) Vaananen A, Kevin MV, Ala-Mursula L, Pentti J, Kivimaki $\mathrm{M}$ and Vahtera J: The double burden of and negative spillover between paid and domestic work: associations with health among men and women. Women Health 40, 1-18 (2004)

9) Weinberg A and Creed F: Stress and psychiatric disorder in healthcare professionals and hospital staff. Lancet 355, 533-537 (2000)

10) Poissonnet CM, Iwatsubo Y, Cosquer M, Quera Salva MA, Caillard JF and Veron M: A cross-sectional study of the health effects of work schedules on 3212 hospital workers in France: implications for the new French work schedules policy. J Hum Ergol (Tokyo) 30, 387391 (2001)

11) Jinks AM, Lawson V and Daniels R: A survey of the health needs of hospital staff: implications for health care managers. J Nurs Manag 11, 343-350 (2003)

12) Tountas Y, Demakakos PT, Yfantopoulos Y, Aga J, Houliara L and Pavi E: The health related quality of life of the employees in the Greek hospitals: assessing how healthy are the health workers. Health Qual Life Outcomes 1, 61 (2003)

13) Walters V: The social context of women's health. BMC Women's Health 4, S2 (2004)

14) Burke RJ and Greenglass ER: Work-family conflict, spouse support, and nursing staff well-being during organizational restructuring. J Occup Health Psychol 4, 327-336 (1999)

15) Bergman B, Ahmad F and Stewart DE: Physician health, stress and gender at a university hospital. J Psychosom Res 54, 171-178 (2003)

16) Suzuki K, Ohida T, Kaneita Y, Yokoyama E, Miyake T, Harano S, Yagi Y, Ibuka E, Kaneko A, Tsutsui T and Uchiyama M: Mental health status, shift work, and occupational accidents among hospital nurses in Japan. J Occup Health 46, 448-454 (2004)

17) Kogi K: International research needs for improving sleep and health of workers. Ind Health 43, 71-79 (2005)

18) Kelloway EK and Gottlieb BH: The effect of alternative work arrangements on women's well-being: a demandcontrol model. Women's Health 4, 1-18 (1998)

19) Barnett RC, Gareis KC and Carr PL: Career satisfaction and retention of a sample of women physicians who work reduced hours. J Women's Health (Larchmt) 14, 146-153 (2005)

20) Carr PL, Gareis KC and Barnett RC: Characteristics and outcomes for women physicians who work reduced hours. J Womens Health (Larchmt) 12, 399-405 (2003) 
21) Emslie C, Hunt K and Macintyre S: Problematizing gender, work and health: the relationship between gender, occupational grade, working conditions and minor morbidity in full-time bank employees. Soc Sci Med 48, 33-48 (1999)

22) Stamps P, Piedmonte E. Nurses and work satisfaction: an index for measurement. Michigan: Health Administration Press, 1986.

23) Acamer Raga F, Lopez Arribas C, Lopez-Torres Hidalgo J: Work satisfaction of health personnel in primary care. Aten Primaria 20, 401-407 (1997)

24) Ware JE Jr. MOT, Health Assessment Lab, Quality Metric Incorporated: SF-36 ${ }^{\circledR}$ Health Survey ${ }^{\odot} 1988$, 2002. IQOL SF-36 Standard German (Austria) Version 1.0-3/94.

25) Bullinger M, Kirchberger I. Der SF-36 Fragebogen zum Gesundheitszustand-Handbuch für die deutschsprachige Fragebogenversion. Göttingen: Hogrefe, 1998.

26) Cheng Y, Kawachi I, Coakley EH, Schwartz J and Colditz G: Association between psychosocial work characteristics and health functioning in American women: prospective study. BMJ 320, 1432-1436 (2000)

27) Budge C, Carryer J and Wood S: Health correlates of autonomy, control and professional relationships in the nursing work environment. J Adv Nurs 42, 260-268 (2003)

28) Ellert U and Kurth BM: Methodological views of the SF-36 summary scores based on the adult German population. Bundesgesundheitsbl-GesundheitsforschGesundheitsschutz 47, 1027-1032 (2004)

29) Wilson D, Parsons J and Tucker G: The SF-36 summary scales: problems and solutions. Soz Praventivmed 45,239-246 (2000)

30) Ware J, Snow K, Kosinski M, Gandek B. SF-36 Health Survey. Manual and Interpretation Guide. Massachusetts: Quality Metric \& the Health Assessment Lab, 2000.

31) Lunz ME, Morris MW and Castleberry BM: Mdical technologist career commitment and satisfaction with job benefits. Clin Lab Manage Rev 10, 613-618 (1996)
32) Lundh U: Job satisfaction among Swedish nurses and laboratory technologists. Br J Nurs 8, 948-952 (1999)

33) Hignett S: Work related pain in nurses. J Advanced Nursing 23, 1238-1246 (1996)

34) Kamwendo K, Linton SJ and Moritz U: Neck and shoulder disorders in medical secretaries. Part II. Ergonomical work environment and symptom profile. Scand J Rehabil Med 23, 135-142 (1991)

35) Waldron I, Herold J, Dunn D and Staum R: Reciprocal effects of health and labor force participation among women: evidence from two longitudinal studies. J Occup Med 24, 126-132 (1982)

36) Wensing M, Vingerhoets E and Grol R: Functional status, health problems, age and comorbidity in primary care patients. Quality of Life Research 10,141-148 (2001)

37) Mastekaasa A and Moum T: The perceived quality of life in Norway: regional variations and contextual effects. Social Indicat Res 14, 385-419 (1984)

38) Abbey A, Andrews SM: Modelling the psychological determinants of life quality. Social Indicators Research 16, 1-34 (1985)

39) Riazi A, Hobart JC, Fitzpatrick R, Freeman JA and Thompson AJ: Socio-demographic variables are limited predictors of health status in multiple sclerosis. J Neurol 250, 1088-1093 (2003)

40) Wood-Dauphinee S: The Canadian SF-36 health survey: normative data add to its value. CMAJ 163, 283-284 (2000)

41) Kempen GIJM, Ormel J, Brilman EI and Relyveld J: Adaptive responses among Dutch elderly: The impact of eight chronic medical conditions on health- related quality of life. Am J Public Health 87, 38-44 (1997)

42) Escriba-Agüir E and Tenias-Burillo T: Psychological well-being among hospital personnel: the role of family demands and psychosocial work environment. Int Arch Occup Environ Health 77, 401-408 (2004)

43) Walters V, Lenton R, French S, Eyles J, Mayr J and Newbold B: Paid work, unpaid work and social support: a study of the health of male and female nurses. Soc Sci Med 43, 1627-1636 (1996) 